\title{
IMPROVING THE RELIABILITY OF THE HYDRAULIC PART OF THE OILFIELD PUMP, TAKING INTO ACCOUNT THE SELECTION OF MATERIAL FOR THE SEAL ASSEMBLY
}

\author{
Ibrahim Abulfaz Habibov ${ }^{1}$ \\ h.ibo@mail.ru \\ Vusala Shakir Huseynova ${ }^{1}$ \\ vusala.huseynova.sh@gmail.com \\ Sevinj Malik Abasova ${ }^{1}$ \\ seva-abasova@mail.ru \\ ${ }^{1}$ Department of Engineering and Computer Graphics \\ Azerbaijan State Oil and Industry University \\ 20 Azadliq ave., Baku, Azerbaijan, AZ 1010
}

\begin{abstract}
Many years of experience in the operation of oilfield equipment during underground well repair shows that ensuring the reliability and durability of the pumping units used is one of the main elements of the process chain, largely determined by the quality and performance characteristics of the friction units of the hydraulic parts of the pumps.

It is known that high-pressure oilfield pumps used in the repair of oil and gas wells carry out various technological works, including cementing, hydraulic fracturing, acid treatment, washing sand plugs and other washing and squeezing operations.

Parts of the hydraulic parts of the pumps are subjected to abrasive, corrosion-mechanical and corrosion-abrasive wear, which often leads to sudden failures, fraught with emergencies, additional costs and loss of time for unscheduled repairs.

The article considers the possibility of increasing the reliability of plunger oilfield pumps due to the correct removal of the material of the sealing collars and improving the assembly scheme. It is also proposed to use the diffusion monotonic distribution as a model of failure to evaluate the reliability function of the selected best compression scheme. Since this distribution model is a more flexible function that better aligns qualified data, compared to the well-known two-parameter strict probability models.

The results of the work have theoretical and practical prerequisites for assessing the reliability of field pumping units and may be useful for specialists working in this field.
\end{abstract}

Keywords: oilfield pumps, hydraulic part, seal assembly, reliability, cuff layout.

DOI: $10.21303 / 2461-4262.2020 .001222$

\section{Introduction}

One of peculiarities in operation of oil-field pumps is rather low level of service life of their hydraulic part. Plunger pair and sealing cuff while in service are exposed to intensive deterioration that promotes a premature stop of pump installation with the subsequent replacement of these details and units and to increase in expenses of time at repair.

Piston and plunger pumps of a high pressure are applied in drilling wells, at various influences on borehole zone of layers, clearing of wells and some other works. In the majority of the listed technological operations a details of a hydraulic part of pumps are exposed to wear process by an abrasive layer (pistons, plungers, cylinder cartridges, rods) and to percussion - abrasive wear process (breech blocks and saddles of the valve). In this connection important value is given to selection of condensation units' construction in pumps.

The service life of piston pumps is limited by the operability of wearing parts and components of its hydraulic part. The reliability of the latter depends on the wear resistance of parts and components of the cylinder-piston group and valve pairs [1,2]. The increased wear rate of parts of the hydraulic part of the pump is due to the content of abrasive particles in the pumped liquid, the action of high contact stresses on the working surfaces of the main parts and components of the 
hydraulic part, as well as the cyclic and impact nature of the loads on the working surfaces of the above parts and assemblies. The high performance of the pumps also depends on the reliability of the seal assembly.

This article [3] examined in detail the working ability of oilfield pumps, and found that their efficiency is largely determined by the reliability of the plunger assembly and valves. The author of [4] proposes to improve both the mechanical and hydraulic parts of it in order to increase the operability of piston pumps in drilling and field pumps. Special attention is paid to valves and plunger couples.

From the analysis of the results of the above works it was established that the main cause of their failures is mechanical, abrasive and hydro abrasive wear.

Usually at research of reliability of separate details of pumps for refusal of a detail the size of its deterioration is accepted and the elementary model of linear deterioration is used

$$
\eta(t)=\alpha t+\beta
$$

where $\alpha$-speed of wear process, $\beta$ - initial value of deterioration: $\beta=\eta(0)$. Random variations of value $\alpha$ reflect distinction of initial properties of the object providing various speeds of deterioration.

In the assumption, as $\alpha$ and $\beta$ - the independent random variables, submitting to normal distribution (and therefore, $\eta(t)$ has normal distribution), receive distribution of operating time $\tau$ as Bernstein's well-known dispersive distribution [5]. So, in work [6] with the help of Bernshtein's distribution it is received wear resistance of the piston pump's rods by results of their bench tests. At this time presence (before infringement of tightness in interfaces and transition in a state of catastrophic wear process) the established rectilinear site of a curve of wear process of a detail in time with differing speeds of wear process of the samples, dependent on initial quality of their manufacturing and assembly is supposed.

Let's suppose that distribution of random values $\alpha$ also $\beta$ submit to the normal law, proceed from the following habitual reasons. Values $\alpha$ also $\beta$ are the sum of the big number $N$ items, each of which is a component of the speed, arising under influence of any one physical process (abrasive, fatigue, oxidizing and others wears). If all items have the identical order it is possible to accept, that their sum it will be good to follow the normal law. Thus central limiting theorem of the theory of probability which is validity at enough large number $N \rightarrow \infty$ of items, in essence, is used. For final $N$ the statement of this theorem can and not be carried out.

The analysis of works under the theory of reliability [7] shows that use of normal distribution in theoretical models of distribution of an operating time is one of the reasons of the unsatisfactory decision of reliability's tasks for mechanical objects (details of machines and systems). However investigators use in the given appendix normal distribution from considerations of calculation convenience (simplicity of formular expressions) with the subsequent essential methodical errors in an estimation of reliability's required parameters.

The analysis of sufficiently voluminous modeling results for various types of empirical distributions showed that often statistics are fairly well described by almost all two-parameter distribution functions: diffusion-monotonic (DM), diffusion-nonmonotonic (DN), normal (N), logarithmically normal (LN) and Weibull (W).

The aim of research is to increase the reliability of oilfield pumps due to the correct selection of sealant materials and their layout.

Based on this, the tasks and problems associated with the choice of material for the manufacture of the cuff of the seal assembly and the layout of their layout, as well as a model for assessing reliability in the considered time period, were posed and solved.

\section{Materials and methods of research}

As an object of research, a unit of a plunger pair (plunger and sealing cuffs) of serial oilfield pumps NP-100, 4NP-500 and N5-160 is adopted. These pumps are used in the designs of mobile 
pumping units UN1-100x200, UNS1-160x50 and UPNB1-100x25, produced by Sabunchu Scientific and Production Association [7].

As one of kinds of a material the composition on a basis ftoroplast marks FT4A and composite material (SKN4O+SKEPT60+PVCH10) was used. As fillers were taken: graphite PG-1 and nano-copper, with sizes of 60-80 $\mathrm{nm}[8,9]$.

The laboratory testing technique was carried out according to the recommendations $[8,9]$, which examined almost the entire set of modern methods used for testing polymer materials.

The probability-physical approach to research of reliability of machines and equipments is based on use of distribution laws for refusals (models of reliability), following from the analysis of physical processes of degradation and bringing to refusal. Thus physical processes of degradation are considered as random processes. This approach directly establishes connection of probability for achievement of a marginal level by physical determining parameter, i. e. connects value of probability of refusal and the physical parameter causing refusal. Distribution of refusals (distribution of an operating time to refusals) which parameters have concrete physical interpretation, as against strict probability distributions (models) of refusals (exponential, Weibull, logarithmic normal, etc.), it is accepted to name distribution of refusals by probability - physical distribution (model) of refusals.

In $[10,11]$ the detailed comparative analysis of existing circuits of formalization of probability-physical models of refusals is given. Thus four circuits of formalization are considered:

1) fan random process to which there corresponds alpha - distribution;

2) "strongly hashed" Gauss process to which there corresponds normal parametrical distribution;

3) continuous markof process with monotonous realizations to which corresponds diffusion monotonous distribution (DM - distribution);

4) continuous markof process with nonmonotonic realizations to which corresponds diffusion nonmonotonic distribution ( $\mathrm{DN}$ - distribution).

In GOST 27.005 and GOST 3942 it is shown, that diffusion distributions (DM and DN) are more flexible functions better leveling the skilled data in comparison with known two-parametrical is strict probability models (Weibull, logarithmic normal, gamma - distribution, etc.), and also in comparison with normal parametrical and alpha - distribution. Besides diffusion, distributions are represented by rather simple functions having simple expressions for various estimations of the parameters, and also for all basic parameters of reliability.

Diffusion distributions as probability - physical models of reliability have the big advantage before strict probability models that their parameters can be estimated as on the basis of refusals statistics (in this case they are considered as strictly probability models), and on the basis of the analysis of statistical characteristics of the physical process bringing to refusal, and also at jointly use of statistical information on both types. The major factor promoting the decision of various of reliability's tasks at use diffusion distributions is that the form parameter of these distributions represents the generalized characteristic of investigated mutually reversible processes (process of destruction and distribution of an operating time) - factor of a variation. And the factor of a variation as the generalized characteristic with sufficient accuracy for engineering practice can be estimated a priori on the basis of numerous researches as processes of destructions (durability, weariness, wear process, etc.), and the statistical data on refusals under tests and exploits of products - analogues.

\section{Research results}

For test of samples condensation unit let's accept 3 circuits:

1) the unit of condensation will consist only from FT4A, and each package will consist of 4 cuffs $\mathrm{V}$ - figurative type;

2) the unit of condensation is made from FT4 and rubbers of mark IP-1293;

3) the unit of condensation will consist of configuration FT4 and SKN40+SKEPT60+PVC10.

For each chosen circuit 10 complete sets are exposed to test. The statistics of refusals of pump installations under each chosen circuit of units of condensation is resulted in Table $\mathbf{1 .}$ 
Table 1

Operating time obtained for various materials sealing cuffs

\begin{tabular}{|c|c|c|c|c|c|c|c|c|c|c|c|}
\hline \multirow{2}{*}{$\begin{array}{l}\text { The circuits of } \\
\text { condensation }\end{array}$} & \multirow{2}{*}{$\begin{array}{c}\text { A material of condensation } \\
\text { cuffs }\end{array}$} & \multicolumn{10}{|c|}{ Value of operating tike for group of condensations } \\
\hline & & 1 & 2 & 3 & 4 & 5 & 6 & 7 & 8 & 9 & 10 \\
\hline & $\begin{array}{l}\text { Ftoroplast FT4A with the } \\
\text { maintenance of } 10 \% \text { of } \\
\text { graphite }\end{array}$ & 340 & 352 & 310 & 361 & 340 & 370 & 372 & 350 & 366 & 371 \\
\hline & Ftoroplast and rubber & 290 & 295 & 270 & 301 & 295 & 293 & 300 & 260 & 280 & 277 \\
\hline & $\begin{array}{c}\text { Ftoroplast FT4A and } \\
\text { SKN40+SKEPT } 60+\text { PVC10 }\end{array}$ & 326 & 374 & 380 & 350 & 380 & 379 & 385 & 401 & 392 & 400 \\
\hline
\end{tabular}

Methodology of an establishment of quantity indicators of objects' reliability on the basis of the statistical data on refusals at tests or while in exploit provide acceptance of this or that theoretical model of refusals (function of distribution of an operating time to refusal or on refusal) and definition of parameters of this of distribution function.

With this as theoretical function for distribution of an operating time to refusal of pump installation's condensation unit diffusion monotonous (DM) distribution. Integral function of this distribution has the following simple expression

$$
F(t)=D M(t, \mu, v)=\Phi\left(\frac{t-\mu}{v \sqrt{\mu t}}\right)
$$

where

$$
\Phi(z)=\frac{1}{\sqrt{2 \pi}} \int_{-\infty}^{z} \exp \left(-\frac{x^{2}}{2}\right) \mathrm{d} x
$$

is the normalized normal distribution; $\mu$ - the parameter of scale concedes to a distribution's median of a random variable $t ; \mathrm{v}$ - parameter of the distribution's form for a random variable $t$, the representing factor of a variation; $t$ - an operating time to refusal.

Let's estimate parameters DM - distributions separately for each of three circuits of condensation on the basis of the statistical data on its refusals at the plan of full tests (the plan [NUN]) ( $N=10$ tests), submitted in the corresponding line of Table 1. The most widespread and effective from the theoretical point of view a method of definition of a sample estimation of parameters distribution's parameters is the method of maximal plausibility (MP).

The given method, as is known, possesses the important advantages: it always results in well - off estimations (which efficiency grows with increase in volume of sample), having the least possible dispersion and in the best way using the information on the unknown parameter, contained in sample.

MP-estimations for distribution's parameters are received from function of the maximal plausibility

$$
L=\prod_{i=1}^{N} f_{M}\left(t_{i} ; \mu, v\right)
$$


where $t_{1}, t_{2}, \ldots, t_{N}$ - operating time to refusal $\left(N-\right.$ number of the samples put on test); $f_{M}\left(t_{i} ; \mu, v\right)-$ density of probabilities of DM-distributions:

$$
f_{M}(t ; \mu, v)=\frac{(\mu+t)}{2 v t \sqrt{2 \pi \mu t}} \exp \left[-\frac{(\mu-t)^{2}}{2 v^{2} \mu t}\right]
$$

Taking the logarithm equality (2), with the account (3), let's receive

$$
\ln L=\sum_{i=1}^{N}-\frac{N}{2} \ln \mu-\sum_{i=1}^{N}\left(2 t_{i} \sqrt{2 \pi t_{i}}\right)-\sum_{i=1}^{N} \frac{\left(\mu-t_{i}\right)^{2}}{2 v^{2} \mu t_{i}} .
$$

The maximum of function (4) is finded from the decision of system of the equations

$$
\left\{\begin{array}{l}
\frac{\partial \ln L}{\partial \mu}=0 \\
\frac{\partial \ln L}{\partial v}=0
\end{array}\right.
$$

In designations

$$
\theta=N\left[2 \sum_{i=1}^{N}\left(\mu+t_{i}\right)^{-1}\right]^{-1}, G=N\left(\sum_{i=1}^{N} t_{i}^{-1}\right)^{-1}, S=\frac{1}{N} \sum_{i=1}^{N} t_{i}
$$

the first equation of system (5) will be written down as

$$
v^{2} \mu^{2} \theta^{-1}-\mu^{2} G^{-1}-\mu v^{2}+S=0
$$

And the second - as

$$
2+v^{2}-\mu G^{-1}-\frac{S}{\mu}=0
$$

Thus, MP-estimations $\tilde{\mu}, \tilde{v}$ of parameters $\mu, v$ are determined from the decision of the following system of the equations

$$
\left\{\begin{array}{l}
\tilde{v}^{2} \tilde{\mu}^{2} \theta^{-1}-\tilde{\mu}^{2} G^{-1}-\tilde{\mu} \tilde{v}^{2}+S=0 \\
2+\tilde{v}^{2}-\tilde{\mu} G^{-1}-\tilde{\mu}^{-1} \cdot S=0 .
\end{array}\right.
$$

From the second equation of system (9) let's find

$$
\tilde{v}^{2}=\tilde{\mu} G^{-1}+\tilde{\mu}^{-1} S-2
$$

Having made replacement $\tilde{v}^{2}$ in the first equation, let's receive a quadratic concerning parameter $\tilde{\mu}$ :

$$
\tilde{\mu}^{2}-2 \tilde{\mu}(G+\theta)+2 \theta G+G S=0 .
$$

The unique decision of last equation under condition of $G<\tilde{\mu}<S$ results in expression of MP-estimations $\tilde{\mu}$ of parameter $\mu$.

Thus, MP-estimations of DM - distribution's parameters following from the decision of system (9) have the following kind [12]: 


$$
\begin{gathered}
\tilde{\mu}=G+\theta-\left(G^{2}-S G+\theta^{2}\right)^{1 / 2}, \\
\tilde{v}=\left(\tilde{\mu} G^{-1}+\tilde{\mu}^{-1} S-2\right)^{1 / 2} .
\end{gathered}
$$

For a simplified estimate is used

$$
\tilde{\mu}=(S G)^{1 / 2} \text {. }
$$
coincide.

Also it is marked, that at enough large $N$ (more than 100) estimations (11) and (13) practically

Let's notice that by virtue of first of designations (6) $\theta \approx \theta(\mu)$ and at substitution in the equation (11) instead of $\theta$ a corresponding estimation

$$
\tilde{\theta}=\theta(\tilde{\mu}) \equiv N\left[2 \sum_{i=1}^{N}\left(\mu^{2}+t_{i}\right)^{-1}\right]^{-1}
$$

the system of the nonlinear equations concerning unknown persons $\tilde{\mu}$, $\tilde{v}$ will turn out:

$$
\left\{\begin{array}{l}
\tilde{\mu}=G+\theta(\tilde{\mu})-\left(G^{2}-S G+\theta^{2}(\tilde{\mu})\right)^{1 / 2} \\
\tilde{v}=\left(\tilde{\mu} G^{-1}+\tilde{\mu}^{-1} S-2\right)^{1 / 2}
\end{array}\right.
$$

For solving the system (15) it is possible to apply iterative procedure

$$
\left\{\begin{array}{l}
\tilde{\mu}_{n}=G+\theta\left(\tilde{\mu}_{n-1}\right)-\left(G^{2}-S G+\theta^{2}\left(\tilde{\mu}_{n-1}\right)\right)^{1 / 2}, \\
\tilde{v}_{n}=\left(\tilde{\mu}_{n} G^{-1}+\tilde{\mu}_{n}^{-1} S-2\right)^{1 / 2},(n=1,2, \ldots),
\end{array}\right.
$$

having taken for initial values of calculated parameters

$$
\tilde{\mu}_{0}=(S G)^{1 / 2}, \quad \tilde{v}_{0}=\left(\tilde{\mu}_{0} G^{-1}+\tilde{\mu}_{0}^{-1} S-2\right)^{1 / 2} \text {. }
$$

Let's make calculation of parameters $\tilde{\mu}, \tilde{v}$ for the first circuit of condensation, sample of values of an operating time to which refusal is submitted by a variational series (Table 1).

\section{Discussion of the results of experimental studies}

In contrast to standard cases, where to assess the reliability of the sealing unit of oilfield pumps, the basis is the amount of wear with a linear nature of the change, which is accompanied by significant errors and makes it difficult to predict their likelihood of failure operation. In our opinion, the main reason for the unsatisfactory solution of problems of this nature is that the normal distribution law is used as a theoretical model for the distribution of failures. Well-known recommendations on the use of the normal distribution in reliability problems with a coefficient of variation of the distribution of operating time less than 0.25 . Whereas, the coefficient of variation of the operating time of almost any technical objects exceeds 0.25 .

The proposed probabilistic-physical model of reliability based on diffusion distributions is a new technology for studying the reliability of technical systems, regardless of the type of product.

It has important advantages: it always leads to consistent estimates (the effectiveness of which increases with increasing sample size), which has the smallest possible variance and makes the best use of all the information about an unknown parameter contained in the sample. Two-parameter diffusion distributions (DM- and DN- distributions) determine the most complete reliability characteristics - distribution time between failures (to failure, failure, resource, etc.), which allow to evaluate any reliability indicators (average operating time, gamma percentage resource, probability of failure-free operation for a given operating time interval, residual life, etc.). 
The following examples show the validity of the above reasoning.

For the first compression scheme, the sample of the mean time between failures, which is represented by the variational series:

$$
310,340,340,350,352,361,366,370,371,372 .
$$

From two last formulas (6) let's find $G=352.48, S=353.2$.

From formulas (17) let's find $\tilde{\mu}_{0}=352.8, \tilde{v}_{0}=0.043$.

Let's calculate $\tilde{\theta}_{0}=\theta\left(\tilde{\mu}_{0}\right): \tilde{\theta}_{0}=354.56$.

From formulas (16) at $n=1$ let's find $\tilde{\mu}_{1}=352.798, . \tilde{v}_{1}=0.044$.

So, after the first iteration of procedure (16) let's have $\tilde{\mu}_{1} \approx 352.8, \tilde{v}_{1}=0.044$ to within the second and third sign accordingly. More exact values can be received, applying this procedure for $n=2,3, \ldots$.

Estimations $\tilde{\mu}, \tilde{v}$ for the second and third circuit of condensation are finded similarly. (Table 1):

So, for the second circuit let's have a variation series of an operating time to refusal

$$
\text { 260, 270, 277, 280, 285, 290, 293, 295, 300, } 301 .
$$

Then

$$
\begin{gathered}
G=284.52, S=285.1, \quad \tilde{\mu}_{0}=284.81 \\
\tilde{v}_{0}=0.0448, \quad \tilde{\theta}_{0}=284.82, \quad \tilde{\mu}_{1}=284.809, \quad \tilde{v}_{1}=0.0447 .
\end{gathered}
$$

So, after the first iteration let's have $\tilde{\mu}=284.81$ and $\tilde{v}=0.045$ to within the second and third sign accordingly.

For the third circuit of condensation a variation series of operating time to refusal looks like:

$$
326,350,374,379,380,380,385,392,400,401 .
$$

Parameters $G$ and $S$ in this case have the following values

$$
\begin{gathered}
G=375.35, \quad S=367.7, \quad \tilde{\mu}_{0}=376.02 \\
\tilde{v}_{0}=0.059, \quad \tilde{\theta}_{0}=376.047, \quad \tilde{\mu}_{1}=376.02
\end{gathered}
$$

So here it is possible to accept $\tilde{\mu}=376.02$ and $\tilde{v}=0.059$ to within the second and third sign accordingly.

Thus, for considered three circuits of condensation integral functions of distribution will be written down accordingly as:

$$
\begin{gathered}
F(t)=\Phi\left(\frac{t-352.80}{0.044 \sqrt{352.80 \cdot t}}\right), \\
F(t)=\Phi\left(\frac{t-284.81}{0.045 \sqrt{284.81 \cdot t}}\right), \\
F(t)=\Phi\left(\frac{t-376.02}{0.059 \sqrt{376.02 \cdot t}}\right) .
\end{gathered}
$$

As the maximal operating time to refusal under the second circuit is equal $301 \mathrm{~h}$., it is natural to compare values of function of reliability $1-F(t)$ of considered three circuits at $t=300 \mathrm{~h}$. 
For the first circuit let's have:

$$
\begin{aligned}
& 1-F(300)=1-\Phi\left(\frac{300-352.8}{0.044 \sqrt{352.8 \cdot 300}}\right)= \\
& =1-\Phi(-3.69)=\Phi(3.69)=0.99989
\end{aligned}
$$

for the second circuit:

$$
\begin{aligned}
& 1-F(300)=1-\Phi\left(\frac{300-284.81}{0.045 \sqrt{284.81 \cdot 300}}\right)= \\
& =1-\Phi(1.15)=0.12507 ;
\end{aligned}
$$

and at last, for the third circuit:

$$
\begin{aligned}
& 1-F(300)=1-\Phi\left(\frac{300-376.02}{0.059 \cdot \sqrt{376.02 \cdot 300}}\right)= \\
& =1-\Phi(-5.03)=\Phi(5.03) \succ 0.99997 .
\end{aligned}
$$

From here follows, that more reliable is the third circuit of condensation. At calculation of function of standard normal distribution $\Phi(x)$.

\section{Conclusion}

As a seal in oilfield pumps, a combined cuff design is proposed, consisting of ftoroplast FT4A and SKN40+SKEPT 60+PVC10.

In contrast to the standard approach for assessing the reliability of failures due to wear of machine parts (a model of a linear change in the wear rate over time), the use of the not necessarily linear nature of the change in operating characteristics using diffusion monotonic (DM) distributions as a model of failures is proposed. Since with the use of this model it is possible to evaluate the reliability function of each individual assembly unit of the pumping unit and select the best scheme for the highest value of the reliability function for the considered time period.

The iterative procedure proposed in this paper for estimating the parameters of a given distribution quickly (almost in 2-3 steps) converges to the limiting values.

\section{References}

[1] Kharisov, M. I., Zabirov, F. S. (2019). Substantiation of improvement directions of piston drilling pump valve parts for their failure and tightness improving. Oil and Gas Business, 2, 112-127. doi: https://doi.org/10.17122/ogbus-2019-2-112-127

[2] Valitov, M. Z. (2018). On the question of increase of the resource of units of the cylinder-piston unit of drilling and oilpump pumps. Materialy Mezhdunarodnoy nauchno-prakticheskoy konferentsii «Dostizheniya, problemy i perspektivy razvitiya neftegazovoy otrasli» Al'met'evsk: Izd-vo Al'met'evskogo gosudarstvennogo neftyanogo institut, 342-249. Available at: https://www.elibrary.ru/item.asp?id=32861062

[3] Zhou, B. (2016). Methods Discussing to Improve The Efficiency of Pumping Unit Well System. Proceedings of the 2016 4th International Conference on Machinery, Materials and Computing Technology. doi: https://doi.org/10.2991/icmmct-16.2016.174

[4] Nikolich, A. S. (1996). Sovershenstvovanie i spetsializatsiya porshnevyh nasosov dlya bureniya i dobychi nefti i gaza. Chemical and Petroleum Engineerig, 32, 157-162.

[5] Okladnikova, E. N., Sugak, E. V. (2005). Probabilistic estimate of knots friction and wear resource. Sibirskiy zhurnal nauki i tehnologiy, 148-151.

[6] Sin', T. (2011). Tribologiya i dinamika dvigatelya i silovoy ustanovki. Woodhead Pablishing, 1088.

[7] Babaev, S. G., Kershenbaum, V. Ya., Gabibov, I. A. (2020). Evolyutsiya i nadezhnost' v kompleksah «kachestvo-konkurentosposobnost'» neftegazopromyslovogo oborudovaniya». Moscow: Natsional'niy institut nefti i gaza, 430.

[8] Dyshin, O. A., Habibov, I. A., Shamilov, V. M., Rustamova, K. B. (2019). The structure of interfacial regions in polymer nanocomposites. PNRPU Mechanics Bulletin, 3, 140-148. DOI: HTTPS://DOI.ORG/10.15593/PERM.MECH/2019.3.14

[9] Dyshin, O. A., Habibov, I. A., Rustamova, K. B. (2018). The properties of the structure of disperse-filled polymer composites. PNRPU Mechanics Bulletin, 2, 24-31. doi: https://oi.org/10.15593/perm.mech/2018.2.03 
[10] Grell'man, V., Seydler, S.; Malkin, A. Ya. (Ed.) (2010). Ispytaniya plastmass. Moscow: Nauchnye osnovy i tehnologii, 720.

[11] Shah, V.; Malkin, A. Ya. (Ed.) (2009). Spravochnoe rukovodstvo po ispytaniyam plastmass i analizu prichin ih razrusheniya. Moscow: Nauchnye osnovy i tehnologii, 736.

[12] Strel'nikov, V. P. (2007). Parametricheskaya DM raspredeleniya. Matematichekie mashiny i sistemy, 2, 117-124.

\title{
ENHANCING EFFICIENCY OF USING ENERGY RESOURCES IN HEAT SUPPLY SYSTEMS OF BUILDINGS WITH VARIABLE OPERATION MODE
}

\author{
Oleksandr Klymchuk \\ aaklymchuk@gmail.com \\ Alla Denysova ${ }^{1}$ \\ alladenysova@gmail.com \\ Gennadiy Balasanian \\ balasanyan@opu.ua \\ Lidiia Ivanova \\ leesoul18@gmail.com \\ Olena Bodiul \\ Department of Information Technologies and Cybersecurity \\ Odessa National Academy of Food Technologies \\ 112 Kanatna str., Odessa, Ukraine, 65039 \\ bodyulolena@ukr.net \\ ${ }^{1}$ Department of Thermal Powel Plants and Energy Saving Technologies \\ Odessa National Polytechnic University \\ 1 Shevchenka ave., Odessa, Ukraine, 65044
}

\begin{abstract}
As a research result, characteristic indicators of the efficiency of using various heat sources in combined heat supply systems were determined. During the study, various schemes for integrating heat accumulators in heat supply systems were considered. Water was used as a battery, which also acts as a coolant. Mathematical modeling of processes in combined heat supply systems using intermittent heating is carried out. The characteristic operating modes of the elements of heat supply systems that take into account the operating modes of heat consumers are determined. Mathematical modeling was carried out using a software package that allows to obtain the distribution of heat power of the heat supply system by its main elements and its characteristic operation modes. According to the research results, a coefficient of thermal power reduction and a coefficient of efficiency of using the heat accumulator volume were proposed. These coefficients allow to evaluate the efficiency of heat sources and the efficiency of using the volume of the heat storage tank. Based on the obtained data, the task was set to optimize the daily load of the heat source, taking into account the installation of the storage tank.

The research results can be used for the reconstruction of heat supply systems of buildings with a two-period operation mode (operation duty) using both traditional and renewable heat sources. This will significantly increase the efficiency of the use of elements of the heat supply system, even out the daily heat generation schedule and increase the service life of the main equipment.
\end{abstract}

Keywords: heat supply system, heat accumulator, intermittent heating, renewable energy sources, building operation modes. 